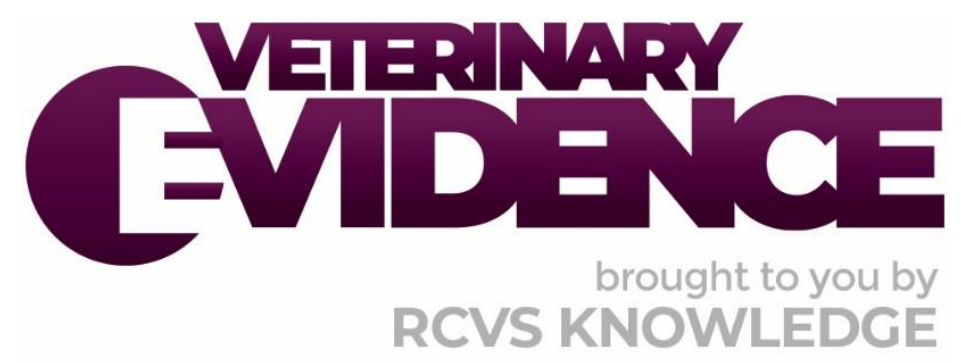

\title{
Insufficient evidence intraperitoneal fluid is equivalent or superior to intravenous fluid therapy in dehydrated calves
}

\author{
A Knowledge Summary by
}

Allan Gunn BVM\&S, MANZCVS, DACT, MRCVS ${ }^{1^{*}}$

Timothy Crawshaw BVetMed, MSc ${ }^{1}$

Victoria Brookes BVM\&S, MANZCVS, PhD, MRCVS ${ }^{1}$

\footnotetext{
${ }^{1}$ School of Animal and Veterinary Sciences, Charles Sturt University, Wagga Wagga, NSW, Australia \& Graham Centre for Agricultural Innovation, (NSW DPI and CSU), Pugsley Place, Wagga Wagga, Australia

*Corresponding Author (algunn@csu.edu.au)
}

ISSN: 2396-9776

Published: 11 Feb 2020

in: Vol 5, Issue 1

DOI: $10.18849 / V E . V 5 I 1.218$

Reviewed by: Virginia Sherwin (MA, VetMB, MVM Dip., ECBHM, MRCVS)and Dai Grove-White (BVSC, MSc, DBR, PhD, DECBHM, FRCVS)

Next Review Date: May 8th 2020 
KNOWLEDGE SUMMARY

\section{PICO question}

In calves $<14$ days old which are moderately to severely dehydrated (5-9\%) or acidaemic (base excess -5 to $-15 \mathrm{mM}$ ), does intraperitoneal fluid therapy result in comparable or superior clinical improvement when compared to intravenous fluid therapy?

\section{Clinical bottom line \\ Category of research question}

Treatment

The number and type of study designs reviewed

Two papers were critically reviewed (one randomised clinical trial and one case series)

Strength of evidence

Weak evidence relevant to the topic question

\section{Outcomes reported}

Statistically significant differences were not found between treatment groups (administration of intravenous fluids [ $n=27$ ] or intra-peritoneal fluids [ $=28]$ ) in the clinical trial, and findings relevant to the topic question were not reported in the case series of 18 calves

\section{Conclusion}

These studies provide insufficient evidence that intraperitoneal (IP) fluid is comparable to, or provides superior clinical improvement, when compared to intravenous (IV) fluid therapy in moderately to severely dehydrated (5-9\%) or acidaemic calves (base excess -5 to $-15 \mathrm{mM}$ ) aged $<14$ days of age

\section{How to apply this evidence in practice}

The application of evidence into practice should take into account multiple factors, not limited to: individual clinical expertise, patient's circumstances and owners' values, country, location or clinic where you work, the individual case in front of you, the availability of therapies and resources.

Knowledge Summaries are a resource to help reinforce or inform decision making. They do not override the responsibility or judgement of the practitioner to do what is best for the animal in their care.

\section{Clinical Scenario}

A group of diarrhoeic calves $<14$ days old are presented for clinical examination and treatment. The calves are in differing stages of dehydration and mentation. Fluid therapy is indicated. In mildly affected calves, oral rehydration therapy will probably suffice, whilst the moderately to severely affected calves will require parenteral intravenous fluid therapy, and potentially supplementary bicarbonate to treat acidaemia. Intravenous fluid therapy can be time consuming and expensive. In moderately dehydrated or acidaemic calves, would intraperitoneal fluid administration be as least as clinically beneficial as intravenous fluid therapy? 


\section{The evidence}

Two studies were identified in which IP fluid was administered to dehydrated calves. Koenig et al. (1995) describe a randomised controlled trial in which 55 calves received either IP or IV fluid. Correction of dehydration and acidaemia was not assessed; instead, longer-term impacts (weight gain and survival) were measured. Significant differences were not detected between treatment groups, but sample size was likely too small to provide sufficient power. The second study is a case series in which some calves were administered IP fluids (McSherry \& Ginyer, 1954). An association between fluid therapy and clinical outcomes was not investigated.

Therefore, these studies do not provide evidence that IP fluids lead to comparable or superior clinical improvement when compared to IV fluid therapy in moderately to severely dehydrated or acidaemic calves.

\section{Summary of the evidence}

\begin{tabular}{|c|c|}
\hline Population: & $\begin{array}{l}\text { Male Holstein calves aged } 1-16 \text { days with clinical dehydration (6-8\%) } \\
\text { and an inability to suck, resident on a Californian calf ranch }\end{array}$ \\
\hline Sample size: & 55 calves \\
\hline Intervention details: & $\begin{array}{l}\text { - Calves were randomly assigned to two treatment groups: } \\
\text { O IV fluid treatment group }(n=27) \\
\text { O IP fluid treatment group }(n=28) \text {. } \\
\text { - The same warmed commercial electrolyte solution (unknown } \\
\text { composition) was administered to all calves in both groups. } \\
\text { - The same calculation ( } \mathrm{kg} x \text { estimated dehydration [\%]) was used to } \\
\text { determine volume of fluid administration to all calves in both groups }\end{array}$ \\
\hline Study design: & Experimental, randomised, controlled trial \\
\hline Outcome studied: & $\begin{array}{l}\text { - Weight gain to } 28 \text { days post-treatment (kg, objective). } \\
\text { - } \text { Survival rates to } 60 \text { days post-treatment (count, objective). } \\
\text { - } \text { days post-treatment (observation, subjective). } \\
\text { - Primary reason for death in all calves that died to } 60 \text { days post- } \\
\text { treatment (count, objective; primary reason for death, potentially } \\
\text { subjective). }\end{array}$ \\
\hline $\begin{array}{l}\text { Main findings: } \\
\text { (relevant to PICO question): }\end{array}$ & $\begin{array}{l}\text { - Weight gain was } 0.9 \text { kg greater in the IV treated group than the IP } \\
\text { group. This finding is not statistically significant. } \\
\text { - } \text { Four more calves survived in the IV treated group than in the IP } \\
\text { treated group. Days to death and the number that survived in each } \\
\text { group is not provided. A finding of no statistical difference between } \\
\text { group survival rates is reported. } \\
\text { - No difference in pathological changes to the peritoneum was } \\
\text { observed between groups. } \\
\text { - The primary causes of death are not described and the significance } \\
\text { of differences between the groups was not determined. }\end{array}$ \\
\hline
\end{tabular}




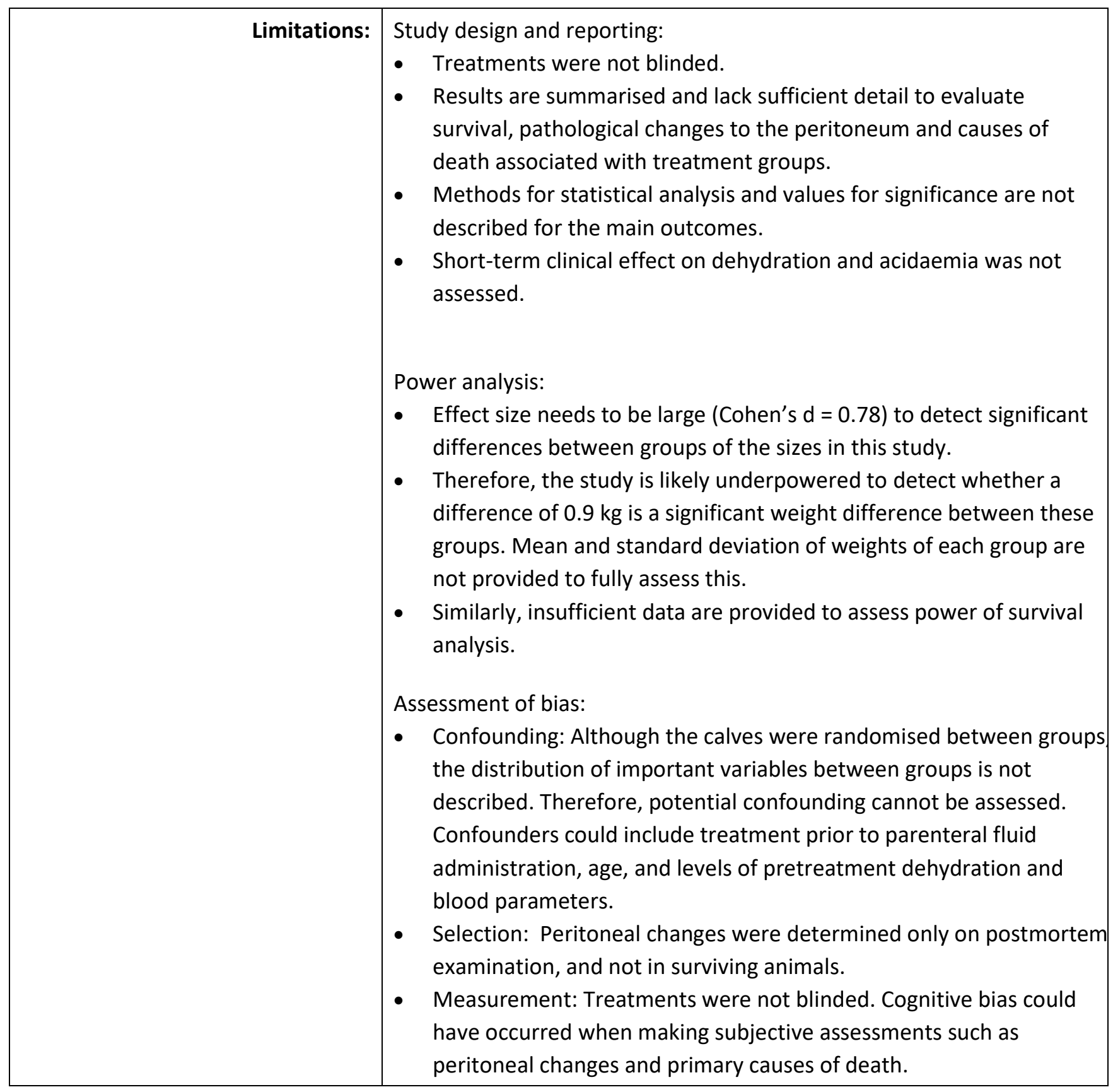

McSherry \& Grinyer (1954)

\begin{tabular}{|r|l|}
\hline Population: & $\begin{array}{l}\text { Jersey, Shorthorn and Holstein Friesian calves with diarrhoea, admitted } \\
\text { to the Ambulatory Clinic of the Ontario Veterinary College, Canada. } \\
\text { Median age was 12.5 days (range 7-90 days). Sex was not specified. }\end{array}$ \\
\hline Sample size: & 18 calves (Jersey = 7, Shorthorn = 7, Holstein Friesian =4) \\
\hline Intervention details: & $\begin{array}{r}\text { Antibiotics including penicillin, streptomycin and unspecified } \\
\text { antibiotics, administered pre- or during clinic admission (reportedly } \\
\text { administered to nine calves). }\end{array}$ \\
& $\begin{array}{l}\text { Unspecified chemotherapeutic agents (reported in three calves) } \\
\text { Oral electrolyte solution - composition not described and } \\
\text { administered to an unspecified number of calves. }\end{array}$ \\
\hline
\end{tabular}




\begin{tabular}{|c|c|}
\hline & $\begin{array}{l}\text { Parenteral electrolyte solution with or without dextrose (5-6 \%) - } \\
\text { reportedly administered to eight calves (one calf received IV fluids, } \\
\text { one calf received IP fluids. The route of administration was not } \\
\text { specified in six calves). Composition of electrolyte fluid is provided in } \\
\text { the manuscript. }\end{array}$ \\
\hline Study design: & Case series \\
\hline Outcome studied: & $\begin{array}{l}\text { - Clinical course of hospitalised calves with diarrhoea (objective and } \\
\text { subjective measurements). } \\
\text { - Repeated objective measurements of selected blood electrolytes } \\
\left(\mathrm{HCO}_{3}, \mathrm{Cl}, \mathrm{Na}, \mathrm{K}, \mathrm{Ca}\right), \mathrm{pH} \text {, sugar and haematocrit in admitted calves. } \\
\text { Sampling interval ranged from 1-4 days. }\end{array}$ \\
\hline $\begin{array}{l}\text { Main findings: } \\
\text { (relevant to PICO question): }\end{array}$ & None that were relevant to the PICO \\
\hline Limitations: & $\begin{array}{l}\text { - No associations are assessed or described between interventions and } \\
\text { clinical signs or blood parameters. } \\
\text { - The paper does not fully describe when and how calves were } \\
\text { administered the electrolyte solution. } \\
\text { - There is no rationale given as to why a stated volume of electrolyte } \\
\text { solution was administered to any given calf. }\end{array}$ \\
\hline
\end{tabular}

\section{Appraisal, application and reflection}

Although intraperitoneal fluid therapy for dehydrated calves has been suggested as equivalent, of greater benefit or of less benefit than other methods of fluid administration, or potentially harmful, these suggestions are not evidence-based.

For example, Roussel (1983) proposed that IP fluid administration was equivalent to oral fluid therapy if dehydration was $<8 \%$. Vermunt (1994) supported this opinion, stating that IV fluids should be administered if dehydration is $>8 \%$. Reasons suggested for equivalency or of greater benefit than other methods of fluid administration include the potential for administration of large volumes (Lewis \& Phillips, 1971) and that IP administration might be a useful method to deliver fluids to the interstitial and intracellular compartments of young animals (Edwards \& Williams, 1972).

In contrast, Radostits (1965) suggested that IP fluid therapy was not beneficial, but stated that this might be due to administration of insufficient volume, and Watt (1967) proposed that it was unsuitable due to the risk of adhesions. Phillips (1985) commented that there were good reasons that IP fluids were not commonly used (without further discussion), and Dickson (1987) recommended that only IV fluids were of benefit in severely dehydrated calves because IP absorption was ineffective. This was reiterated by Michell (1988) who stated that there is no real alternative to IV fluid administration for severe dehydration. More recently, Constable (2003) and González-Montaña et al. (2017) also mention the potential use of IP fluids in cattle and highlight similar risks.

Only two studies were found which claimed to assess intraperitoneal fluid administration of electrolyte solutions to treat dehydration in calves (Koenig et al., 1995 and McSherry \& Grinyer, 1954). In the study by Koenig et al. (1995), authors assessed outcomes in calves at 28 and 60 days post-treatment with IP or IV fluids between 1-16 days old. Although they suggested that IP fluid administration was useful to treat dehydration in young calves (several Californian calf ranches were using this method to administer fluids) this evidence was not presented because it was not the focus of their study. In the study by McSherry \& Grinyer (1954), the 
authors presented clinical and haematological findings from a series of cases in which dehydrated calves were treated with combinations of antibiotics and oral, IP and IV fluids. The clinical benefit of IP fluids relative to IV fluids was not assessed. Importantly, the two studies presented here also did not provide evidence that IP fluid administration does not cause harm (for example, peritonitis).

Overall, we found that there is no evidence to support the use of IP fluids to treat moderate to severe dehydration and acidaemia in calves. Given the lower expected non-clinical costs of IP fluids relative to IV fluids (labour and time) we suggest studies to investigate the safety and clinical benefits of IP fluid administration in calves for this purpose are needed. We propose that IP fluids might be used earlier than intravenous fluid therapy in dehydrated acidaemic calves due to the lower non-clinical costs.

\section{Methodology Section}

\begin{tabular}{|c|c|}
\hline \multicolumn{2}{|l|}{ Search Strategy } \\
\hline $\begin{array}{r}\text { Databases searched and dates } \\
\text { covered: }\end{array}$ & $\begin{array}{l}\text { CAB Abstracts on OVID Platform (1973 - Week } 27 \text { 2018) } \\
\text { Scopus }\end{array}$ \\
\hline Search terms: & 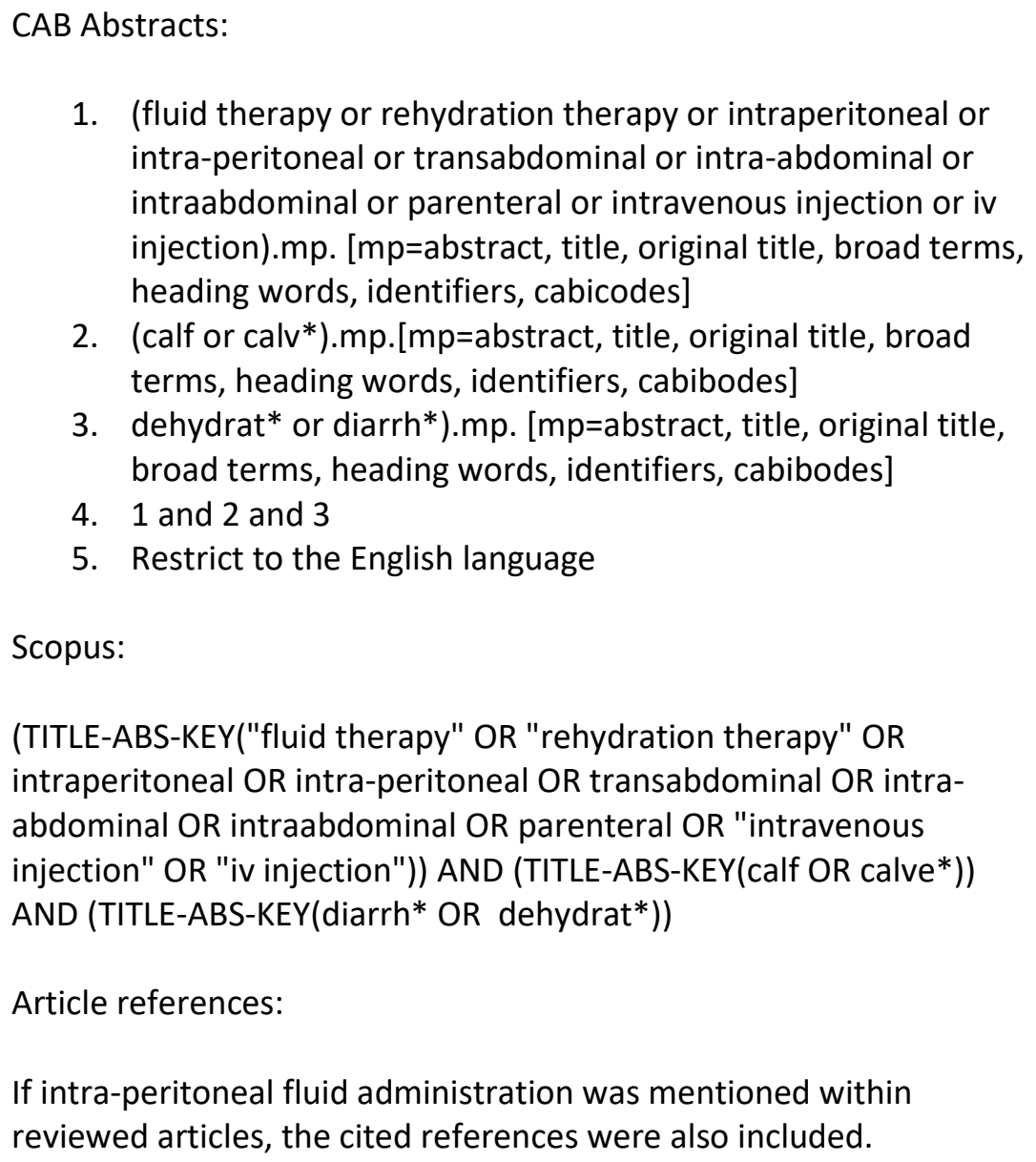 \\
\hline Dates searches performed: & 18/07/2018 \\
\hline
\end{tabular}




\section{Exclusion / Inclusion Criteria}

Exclusion: No mention of intraperitoneal fluid therapy/administration in the title or abstract OR no survey or study occurred.

Literature in languages other than English.

Inclusion: A survey or study in which calves were treated with intraperitoneal administration of an electrolyte solution.

\begin{tabular}{|c|c|c|c|c|c|}
\hline \multicolumn{6}{|c|}{ Search Outcome } \\
\hline Database & $\begin{array}{l}\text { Number of } \\
\text { results }\end{array}$ & $\begin{array}{l}\text { Excluded - } \\
\text { Duplicated in } \\
\text { both searches, } \\
\text { so removed }\end{array}$ & $\begin{array}{l}\text { Excluded - No } \\
\text { mention of } \\
\text { intraperitoneal } \\
\text { fluid } \\
\text { administration in } \\
\text { the title or } \\
\text { abstract }\end{array}$ & $\begin{array}{l}\text { Excluded - No } \\
\text { study carried out }\end{array}$ & $\begin{array}{c}\text { Total relevant } \\
\text { papers }\end{array}$ \\
\hline $\begin{array}{l}\text { CAB Abstracts } \\
\text { on OVID } \\
\text { Platform }\end{array}$ & 323 & 0 & 312 & 11 & 0 \\
\hline Scopus & 182 & 103 & 79 & 0 & 0 \\
\hline $\begin{array}{l}\text { Cited } \\
\text { references } \\
\text { from included } \\
\text { searched } \\
\text { articles }\end{array}$ & 2 & 0 & 0 & 0 & 2 \\
\hline Total relevant & rs when $d$ & tes removed & & & 2 \\
\hline
\end{tabular}

\section{CONFLICT OF INTEREST}

The authors declare no conflicts of interest.

The authors gratefully acknowledge the library assistance of Lee-Anne McInerney (Charles Sturt University), Bridget Sheppard and Clare Boulton (RCVS). 
Constable, P. (2003). Fluid and electrolyte therapy in ruminants. Veterinary Clinics of North America: Food Animal Practice, 19(3), 557-597. DOI: http://dx.doi.org/10.1016/S0749-0720(03)00054-9

Dickson, L. (1987). Fluid therapy in cattle. Proceedings of the 4th Seminar of the Dairy Cattle Society of the New Zealand Veterinary Association held at Rotorua, New Zealand, 18-20 November 1987, 85-89.

Edwards, A. J. \& Williams, L. L. (1972). Fluid therapy in treating dehydration from calf scours (a practical approach). Veterinary Medicine, Small Animal Clinician, 67(3), 273-277.

González-Montaña, J. R., Martin, M. J. \& Alonso, P. (2017). General aspect and current fluid therapy in cattle with digestive diseases. American Journal of Animal and Veterinary Sciences, 12(3), 111-131. DOI: http://dx.doi.org/10.3844/ajavsp.2017.111.131

Koenig, G. J., Holmberg, C. A., Medeiros, R. L. \& Guterbock, W. M. (1995). Comparison between intraperitoneal and intravenous fluid administration in moderately dehydrated calves on a California calf ranch. Proceedings of the Twenty Seventh Annual Convention American Association of Bovine Practitioners, Pittsburgh, Pennsylvania, USA, September 22-25, 1994, 199-200.

Lewis, L. D. \& Phillips, R. W. (1971). Diarrhea in the calf. Part II: Secondary changes and treatment. Proceedings of the American Association of Bovine Practitioners, 109-114.

McSherry, B. J. \& Grinyer, I. (1954). Disturbances in acid-base balance and electrolyte in calf diarrhea and their treatment. A report of eighteen cases. American Journal of Veterinary Research, 15(57), 535-541.

Michell, A. R. (1988). Drips, drinks and drenches: what matters in fluid therapy. Irish Veterinary Journal, 42, $17-22$.

Phillips, R. W. (1985). Fluid therapy for diarrheic calves. What, how, and how much. The Veterinary Clinics of North America: Food Animal Practice, 1(3), 541-562. DOI: https://doi.org/10.1016/S0749-0720(15)31302-5

Radostits, O. M. (1965). Fluid therapy in calf diarrhea. The Canadian Veterinary Journal. 6(7), 180.

Roussel, A. J. (1983). Principles and Mechanics of Fluid Therapy in Calves. Compendium on Continuing Education for the Practicing Veterinarian, 5(6), S332-S336.

Vermunt, J. J. (1994). Rearing and management of diarrhoea in calves to weaning. Australian Veterinary Journal, 71(2), 33-41. DOI: https://doi.org/10.1111/i.1751-0813.1994.tb06149.x

Watt, J. G. (1967). Fluid therapy for dehydration in calves. Journal of the American Veterinary Medical Association, 150(7), 742-750. 


\section{EVIIDEFeE

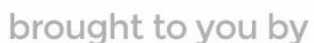 \\ RCVS KNOWLEDGE}

\section{Intellectual Property Rights}

Authors of Knowledge Summaries submitted to RCVS Knowledge for publication will retain copyright in their work, and will be required to grant RCVS Knowledge a non-exclusive license of the rights of copyright in the materials including but not limited to the right to publish, re-

publish, transmit, sell, distribute and otherwise use the materials in all languages and all media throughout the world, and to license or permit others to do so.

\section{Disclaimer}

Knowledge Summaries are a peer-reviewed article type which aims to answer a clinical question based on the best available current evidence. It does not override the responsibility

of the practitioner. Informed decisions should be made by considering such factors as individual clinical expertise and judgement along with patient's circumstances and owners' values. Knowledge Summaries are a resource to help inform and any opinions expressed within the Knowledge Summaries are the author's own and do not necessarily reflect the view of the RCVS Knowledge. Authors are responsible for the accuracy of the content. While the

Editor and Publisher believe that all content herein are in accord with current recommendations and practice at the time of publication, they accept no legal responsibility

for any errors or omissions, and make no warranty, express or implied, with respect to material contained within.

For further information please refer to our Terms of Use.

RCVS Knowledge is the independent charity associated with the Royal College of Veterinary Surgeons (RCVS). Our ambition is to become a global intermediary for evidence based veterinary knowledge by providing access to information

that is of immediate value to practicing veterinary professionals and directly contributes to evidence based clinical decision-making.

https://www.veterinaryevidence.org/

RCVS Knowledge is a registered Charity No. 230886.

Registered as a Company limited by guarantee in England and Wales No. 598443.

Registered Office: Belgravia House, 62-64 Horseferry Road, London SW1P 2AF

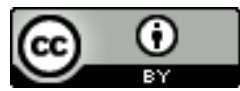

This work is licensed under a Creative Commons Attribution 4.0 International License. 